\title{
Countermeasures for the Sustainable Development of Extracurricular College Physical Education
}

\author{
Aihua Zhu \\ Yunnan Engineering Vocational College, Kunming, Yunnan, 650304
}

Keywords: College Physical Education, Sustainable Development, Countermeasures

\begin{abstract}
The extracurricular sports training in colleges and universities has received much attention. As an important component of regular physical education, it is of great significance to comprehensively improve students' motor skills and overall quality. However, the level of extracurricular sports training and development system in China's colleges and universities are lacking in perfection. This paper takes the problems existing in college sports training as the starting point, and proposes corresponding solutions to the problems, in order to provide college students with extracurricular sports training, providing a reference to improve the problems existing in extracurricular sports training in colleges, and ensure the sustainable development of extracurricular sports training in colleges and universities.
\end{abstract}

\section{Introduction}

Physical education in colleges in China is constantly reforming. In addition to the teaching of regular classroom content, after-school training has become a very important content, and it is gradually becoming standardized. The purpose of carrying out extracurricular sports training is to improve the physical quality of college students, to make the physical and mental development of college students healthy, and to further enrich the after-school life of college students. Therefore, colleges must give enough attention to after-school sports training, and then train more comprehensive and excellent talents. However, the after-school sports training in colleges is still the old model, and the administrative intervention color of the school is more obvious, and there is strong formalism, which is very unfavorable for stimulating students' interest in physical exercise. In addition, the sports facilities are outdated and sometimes there is no corresponding allocation. These practical problems have hindered the effective development of extracurricular training activities in colleges. Colleges and related educators should actively explore the above issues and seek ways and means to improve the effectiveness of after-school sports training.

\section{Analysis of the problems existing in the after-school sports training in colleges}

In the process of college physical education, many leaders pay more attention to physical education and physical education, while the emphasis on extracurricular sports training is significantly lower. At the same time, there is still a certain bias in the recognition of the importance of extracurricular sports training, because they believe that Only through physical education curriculum, under the professional guidance and training of physical education teachers, students' physical quality can be improved, and students' physical education performance can also be improved, which leads to their lack of sufficient attention to after-school sports training, and after-school sports training for students. There are no higher requirements. At present, many college leaders only pay attention to the improvement of students' physical fitness, and hope that they can achieve excellent results in sports games and competitive games. Therefore, they think that the better way is to let physical education teachers specialize in students in physical education classes. Guidance and training, while ignoring the importance of after-school sports training on the development of students' physical and mental qualities. In addition, many university leaders put most of their energy into the education of natural and cultural knowledge, and the emphasis on school sports is significantly lower than other disciplines. Therefore, fundamentally speaking, this 
severely restricts the smooth development of extracurricular sports training in colleges, which naturally leads to insufficient investment in related fields. In short, based on the current situation of the development of extracurricular sports training in colleges in China, the biggest problem is that college leaders pay less attention to extracurricular sports training.

At present, the funds needed for the development of extracurricular sports training in colleges in China mainly come from the following aspects: First, the school and enterprises or industry associations cooperate with the local sports committees to obtain financial support from enterprises, industry associations and local sports committees; The way to raise funds for training; the third is the local government's allocation to the school; the fourth is the allocation of college and university administrative departments for extracurricular sports training. According to the current status quo of college physical education after school, in these sources of funds, the funds for extracurricular sports training mainly come from the funds allocated by the school administration, but rarely from other sources. In addition, many colleges themselves are already struggling with funds for education. At the same time, the status of physical education in college education is not as good as other disciplines. Moreover, college leaders pay less attention to extracurricular sports training, which leads to more The university's capital investment in extracurricular sports training has been greatly reduced, which has seriously restricted the smooth development of extracurricular sports training in colleges, making many training projects difficult to carry out smoothly, and ultimately the effect of college students' extracurricular sports training is greatly reduced.

At present, in the process of enrolling students in China, there is a general phenomenon that the standards are not unified, and the enrollment standards will have a great impact on the effect of after-school sports training. At present, the recruitment methods of physical education students mainly include normal admission, additional entrance examination, exemption from admission, and single entrance examination. Different recruitment methods represent different requirements for students of physical education students, and also indicate that colleges recruit sports students have certain difficult. The main reason for this phenomenon is that many colleges are more inclined to recruit local students. For local students, the recruitment requirements and standards are lower, while for other provinces, physical education students are adding more restrictions, which greatly limits the number of students. The scientific flow and rational allocation of sports talents between provinces and cities has even caused a large amount of waste of sports talent resources, resulting in sufficient resources and competitiveness of some sports talents in some provinces and cities, which has made many athletes unable to obtain scientific training and training, wasting them. Athletic talent. In addition, the resources of sports talents in other provinces and cities are extremely lacking. This phenomenon of uneven distribution of sports talent resources is extremely unfavorable to the development of sports in China. In addition, there are also some unbalanced developments in the pilot work of universities, and the potential advantages of scientific research have not been fully utilized, so that the quality of after-school sports training cannot be really improved.

\section{Strategies for the Sustainable Development of College After-school Sports Training}

Extracurricular sports training is an important part of school physical education activities. The leaders of major universities should clearly and comprehensively interpret the guiding ideology of all kinds of extracurricular sports training, pay attention to physical education, consolidate the foundation of amateur training, and implement extracurricular sports training as part of school education. Physical education is not a simple classroom teaching. Attach importance to excavating and cultivating students with sports specialties, and take it as an important task to attract attention and increase coordination and support for after-school sports training.

Colleges should encourage and reward ordinary physical education teachers for re-learning based on long-term development vision, provide them with learning opportunities and platforms, organize their out-of-school learning and training, so as to learn advanced training methods of similar schools and improve their teaching level. Promote its application of theory to practice, and strive to shift from a part-time role to a high-quality, high-level coach. At the same time, the coaches who are working as extracurricular sports training should actively innovate the training mode, create a 
campus sports culture with their own characteristics to attract students to join, innovate and develop the special sports of the school, and attract students with colorful sports activities as much as possible. Establishing the concept of "Strong physical fitness and building a pillar", such as the "Sports Supermarket" project of Xiamen University is a successful attempt. The school has established a "sports supermarket to attract students' attention, making sports a common practice on campus. Inherited and promoted football, On the basis of traditional projects such as basketball and badminton, you can also carry out personalized training such as rock climbing and off-road for students to choose, but they must take proper protective measures to achieve traditional sports, body shaping, bodybuilding, outdoor development, and size balls. Health care and other training modes for after-school sports, for students to choose according to their own preferences and needs, can open after-school sports training as elective courses.

All colleges should change the concept of teaching, establish a long-acting mechanism of physical education and education, attach importance to cultural education, and also focus on the tempering of physical quality and sportsmanship, so as to achieve both physical education and cultural learning. The current severe social situation determines the pyramid-shaped talent training model of colleges. Only a few people can reach the peak. The society has always followed the principle of survival and the fittest. For the colleges of non-sports majors in sports, the promotion of cultural education and development of sports Training is equally important. After bidding farewell to the campus, students must adapt to the society, improve their ability to survive, and explore new life orientations. Good cultural knowledge learning can enable students to maintain their own competitiveness when they are employed, and provide a broader perspective for their own sustainable development. The development space, and scientific and reasonable after-school sports training can cultivate students' various interests and hobbies, enrich the boring cultural study, and add luster to their future employment.

Perfect after-school sports facilities, equipment and venues are the primary prerequisites for building campus-specific sports. In order to increase the construction of sports facilities, if you open a rock climbing project, you need to build a corresponding base, build an environmental plastic sports field, improve the efficiency of basketball and volleyball courts, and equip with night lights. In addition, the teaching model of the cultural class can be emulated, and the tutor system can be implemented in the after-school physical education. The association can be established according to different projects, and the excellent physical education teachers are selected to be stationed regularly every week. The scope of the guidance includes the arrangement of daily activities and corresponding Sports skills training, sports safety guidance, etc. The selection of the open school sports team, the selection of ordinary students with special skills to join the school sports team, so that more students can exercise under the guidance of special sports instructors and participate in high-level sports. At the same time, we can also give full play to the competitive projects with the advantages of our school, form a fan effect to attract more students out of the dormitory, put down the computer and mobile phone, and go to the playground to carry out sports, so that each sports project has its own "Fans" to ignite the enthusiasm of students for extracurricular sports training.

At present, the evaluation system of extracurricular sports training in colleges is still relatively simple, and it is difficult to stimulate students' enthusiasm for extracurricular sports training. Therefore, colleges should set and improve the after-school training evaluation system according to the basic characteristics of after-school sports training and the physical and mental characteristics of college students. According to the multiple evaluations, such as the number of times, attitudes, practice and scores of students participating in extracurricular sports training, different evaluation methods such as student self-evaluation and mutual evaluation are introduced to promote the autonomy of college students to participate in extracurricular sports training. Enthusiasm.

\section{Conclusion}

The important position of college physical education after school can not be ignored. It has an important contribution to the exploration and cultivation of sports talents. On the basis of strengthening cultural education, we should also pay attention to the cultivation of sports quality. In 
order to achieve sustainable development, college physical education training must go through a long and difficult process. The above experience and experience, practical application effects have yet to be tested, and should be constantly corrected with the changes in educational forms and social situations, only In this way, the sustainable development of college physical education after school can be realized.

\section{References}

[1] YE Ying, MA Ying-xin, WANG Song-tao. Study on the Countermeasures for the Sustainable Development of College Students' Sports Associations [J].Journal of Harbin Vocational and Technical College, 2017(01).

[2]Wang Huafeng. Teaching Reform and Sustainable Development of Extracurricular Sports Training in Colleges [J]. Journal of Hunan City University: Natural Science Edition, 2016(11).

[3] Wang Mingyang. Exploring the Sustainable Development Countermeasures of College Extracurricular Sports Training [J].Contemporary Sports Science and Technology, 2014 (13): 195-196.

[4] Zhang Shi. Research on the Current Situation and Development Countermeasures of Extracurricular Sports Training in Colleges in Southeast Guangxi [J].Journal of Yuzhou University, 2010, 20(3):91-96.

[5] Liu Junhua. Infiltration of moral education in middle school physical education [J]. North and South Bridge, 2016 (3). 